\title{
VISUAL OUTCOME IN SCLERAL FIXATED INTRAOCULAR LENSES
}

\author{
Devendra Saxena ${ }^{1}$, Chaitali Patel ${ }^{2}$
}

${ }^{1}$ Associate Professor, Department of Ophthalmology, Pramukhswami Medical College, Karamsad, Anand, Gujarat. ${ }^{2}$ Assistant Professor, Department of Ophthalmology, Pramukhswami Medical College, Karamsad, Anand, Gujarat.

\begin{tabular}{l}
\hline ABSTRACT \\
\hline OBJECTIVE \\
To find out visual outcome after sclera fixated intraocular lens implantation. \\
METHODS \\
25 patients from 2012 to 2014 who were referred after complicated cataract surgery or had traumatic aphakia leading to \\
dislocated lens and had undergone secondary sclera fixated intraocular lens implantation at our institute by single surgeon under \\
standard operative conditions.
\end{tabular}

\section{RESULTS}

Out of 25 patients, 16 patients had to undergo surgery secondary to cataract surgery related complications. 6 patients had traumatic dislocated lens. 3 patients had undergone previous intracapsular cataract extraction. 10 (40\%) patients had final postoperative visual acuity between $6 / 12$ and 6/9. 9 (36\%) patients had visual acuity of 6/18 to 6/60. 6 (24 \%) patients had visual acuity of $<6 / 60.19$ patients $(76 \%)$ had good visual outcome.

\section{CONCLUSION}

Scleral fixated IOL offer a good alternative for secondary IOL implantation. They are most closely related to natural position of lens as compared to anterior chamber IOL or iris claw lens. Visual outcome is good after sclera fixated IOL and if any posterior segment pathology develops in these patients. It can be managed easily, which is not possible in other secondary IOL's.

\section{KEYWORDS}

Scleral Fixated, IOL, Secondary IOL.

HOW TO CITE THIS ARTICLE: Saxena D, Patel C. Visual outcome in scleral fixated intraocular lenses. J. Evolution Med. Dent. Sci. 2016;5(55):3716-3717, DOI: 10.14260/jemds/2016/852

\section{INTRODUCTION}

In the modern era of phacoemulsification and improved surgical instrumentation, cataract surgery has become one of the safest and gratifying surgical procedure with extreme expectations on part of the patient. They want a spectacle free perfect postoperative outcome.

But, every surgery has its limitations and at times due to technical or structural problems it is not possible to implant IOL during primary procedure. In such patients, the option of secondary IOL in the form of Anterior Chamber IOL (AC-IOL), Iris claw lens, or sclera fixated IOL has to be implanted. AC-IOL and iris claw lens are preferred in view of ease of placement and shorter surgical time.(1) Scleral fixated IOL is the most physiological position for secondary IOL placement, but not preferred by many due to difficult technique and prolonged surgical time.

This study highlights the visual outcome after scleral fixated IOL along with the complications associated with the procedure.(2)

\section{MATERIALS AND METHODS}

The study comprised of 25 patients who had undergone scleral fixated IOL at retina clinic by single surgeon under standard operative conditions.

Financial or Other, Competing Interest: None.

Submission 30-05-2016, Peer Review 29-06-2016,

Acceptance 04-07-2016, Published 08-07-2016.

Corresponding Author:

Dr. Devendra Saxena,

Associate Professor,

Department of Ophthalmology,

Vitreo-Retinal Consultant, PSMC, Karamsad,

Anand-388325, Gujarat.

E-mail: deekaysaxena@yahoo.com

DOI: $10.14260 /$ jemds/2016/852

Their preoperative visual acuity on Snellen chart, anterior segment examination, Intraocular Pressure (IOP) by GAT (Goldmann Applanation tonometry), dilated fundus examination with indirect ophthalmoscope with peripheral indentation to rule out peripheral retinal breaks or retinal degenerations.

Preoperative keratometry was done to assess corneal astigmatism. IOL power for scleral fixated IOL was kept same as for PCIOL (PMMA lens with A-constant of 118.2). Polymethyl Methacrylate (PMMA) scleral fixated IOL with eyelets in the haptics were used. The two haptics were tied at 3 and 9 o'clock position $1 \mathrm{~mm}$ posterior to limbus with Prolene double-armed 10.0 suture.(3,4,5). Anterior vitrectomy was done in 15 cases and core vitrectomy was done in 10 cases who had dropped nucleus.

Anterior chamber maintainer was used during entire procedure and use of viscoelastic material was avoided. Best corrected visual acuity (BCVA) on $1^{\text {st }}$ postoperative day, one week and after 6 week was recorded.

Anterior segment examination and IOP was measured on each visit.

Patients were followed for one year to find out any late complications.

\section{RESULT}

Out of 25 patients 16 had undergone surgery secondary to cataract surgery related complications.

6 patients had traumatic dislocation of lens.

3 patients had primary ICCE surgery done outside.

Pre-Surgery

20 patient BCVA was less than 6/12.

5 patients BCVA $6 / 12$ or better. 


\section{Post-Surgery}

- $10(40 \%)$ patients had BCVA of $6 / 12$ to $6 / 9$.

- $9(36 \%)$ patients had BCVA of $6 / 18$ to $6 / 60$.

- $6(24 \%)$ patients had BCVA of less than $6 / 60$.

- $76 \%$ patients had good visual outcome (6/12-6/60) after scleral fixated IOL as compared to $86 \%$ in iris claw lens.

- 5 patients who had BCVA of less than $6 / 60$ had associated corneal tear secondary to ocular trauma and had undergone corneal tear repair done. One patient had lens tilt with resulting astigmatism of 5 dioptres.

- $\quad$ Out of 25 patients, 13 were 70 yrs. or more.

- 16 were male and 9 were female (1.4:1).

\section{DISCUSSION}

In the modern era, cataract surgery has evolved leaps and bounds, but still every surgery has its limitations and in some cases due to unavoidable circumstances the surgeon is not able to put IOL after cataract surgery. It is a mental trauma for both the surgeon and the patient.

In such circumstances, patient has to undergo another surgery for secondary IOL implantation. Though, we have easy option of AC-IOL or iris claw lens we still prefer to put scleral fixated IOL. $(6,7)$

Our study highlights the visual outcome after scleral fixated IOL. Postoperatively, nearly $40 \%$ patients had BCVA between $6 / 12$ to $6 / 9$ while preoperatively only $20 \%$ patient had BCVA of $6 / 12$ or better.

Total $76 \%$ patients in scleral fixated IOL series had good visual outcome as compared to $86 \%$ in iris claw lens.(8) The advantage of scleral fixated IOL is that any future posterior segment surgery can be done without risk of dislocation or malpositioning of IOL as may happen in iris claw lens.

The improvement in postoperative visual acuity is due to removal of inflammatory, haemorrhagic debris from vitreous along with any vitreous traction leading to macular oedema.

6 patients had BCVA of less than 6/60. 5 patients had undergone corneal tear repair prior to secondary lens implantation.

One patient had lens tilt leading to astigmatism of 5 dioptres.

None of the patient had suture erosion or late onset low grade uveitis on an average follow up of one year.

Scleral fixated IOL should be the preferred method of secondary IOL implantation as it most physiological in position as compared to AC-IOL or iris claw lens. $(9,10,11)$ Both lenses have disadvantage of corneal touch and loss of endothelium in long run and also secondary uveitis and glaucoma.(12) Moreover, such complicated cataract surgery patients are prone to develop some retinal or posterior segment pathology in future and then it becomes easier to examine the posterior segment in scleral fixated IOL where pupil can be medically dilated while this is not possible with AC-IOL or iris claw lens. ${ }^{(13,14)}$

Visual outcome in experienced hand is good enough and so it should become standard of care for secondary IOL implantation.

It needs a larger sample size and prolonged follow up to establish long-term safety and associated complications in scleral fixated IOL's.

\section{REFERENCES}

1. Melamud A, Topilow JS, Cai L, et al. Pars plana vitrectomy combined with either secondary scleral fixated or anterior chamber intraocular lens implantation. Am J Ophthalmol 2016;:S0002-9394(16):30207-0. doi:10.1016/j.ajo.2016.05.006.

2. Haszcz D, Nowomiejska K, Oleszczuk A, et al. Visual outcomes of posterior chamber intraocular lens intrascleral fixation in the setting of postoperative and posttraumatic aphakia. BMC Ophthalmol 2016;16(1):50. doi:10.1186/s12886-016-0228-y.

3. Sorenson R, Scott IU, Tucker SH, et al. Practice patterns of cataract surgeons at academic medical centres for the management of inadequate capsule support for intracapsular or sulcus intraocular lens placement during cataract surgery. J Cataract Refract Surg 2016;42(2):23945. doi:10.1016/j.jcrs.2015.09.022.

4. Sindal MD, Nakhwa CP, Sengupta S. Comparison of sutured versus sutureless scleral-fixated intraocular lenses. J Cataract Refract Surg 2016;42(1):27-34. doi:10.1016/j.jcrs.2015.09.019.

5. Smith JM, Erlanger M, Olson JL. Injectable suture device for intraocular lens fixation. J Cataract Refract Surg 2015;41(12):2609-13. doi:10.1016/j.jcrs.2015.11.013.

6. Agrawal S, Singh V, Gupta SK, et al. Transscleral fixation of closed loop haptic acrylic posterior chamber intraocular lens in aphakic nonvitrectomized eyes. Indian J Ophthalmol 2015;63(8):649-53. doi:10.4103/0301-4738.169797.

7. Forlini M, Soliman W, Bratu A, et al. Long-term follow-up of retropupillary iris-claw intraocular lens implantation: a retrospective analysis. BMC Ophthalmol 2015;15:143. doi:10.1186/s12886-015-0146-4.

8. Patil KB, Meleth P, Prabhu SM. Pars plana vitrectomy with posterior iris claw implantation for posteriorly dislocated nucleus and intraocular lens. Indian Journal of Ophthalmology 2011;59(6):497-500.

9. Kane S, Khurshid GS. Haptic stability of intrascleral fixated posterior chamber intraocular lenses. J Cataract Refract Surg 2015;41(9):2034. doi:10.1016/j.jcrs.2015.09.012.

10. Long C, Wei Y, Yuan Z, et al. Modified technique for transscleral fixation of posterior chamber intraocular lenses. BMC Ophthalmol 2015;15:127. doi: 10.1186/s 12886-015-0118-8.

11. Kelkar A, Shah R, Kelkar J, et al. Sutureless, glueless, scleral fixation of single-piece and toric intraocular lens: a novel technique. Case Rep Ophthalmol 2015;6(2):239-45. doi: 10.1159/000437349.

12. Thompson JM, Chang JS, Magner BJA, et al. Ghost cell glaucoma following sutureless scleral-fixated posterior chamber intraocular lens placement. Ophthalmic Surg Lasers Imaging Retina 2015;46(1):111-13. doi:10.3928/23258160-20150101-22.

13. Sureka SP, Modi RR, Das S. Comparison of outcomes of primary anterior chamber versus secondary scleralfixated intraocular lens implantation in complicated cataract surgeries. Am J Ophthalmol 2015;160(1):201. doi:10.1016/j.ajo.2015.03.014.

14. Kim M, Lee DH, Koh HJ, et al. Surgical outcome of simultaneous intraocular lens rescue and sutureless intrascleral tunnel fixation of dislocated intraocular lenses. Retina 2015;35(7):1450-57. doi:10.1097/IAE.0000000000000484. 